\title{
Atuações educativas de êxito em Goiânia-GO: contribuições à educação básica por meio do PIBID
}

\author{
Keila Matida de Melo * \\ Maria de Fátima Teixeira Barreto ** \\ Vanessa Gabassa ***
}

\section{Resumo}

$\mathrm{O}$ artigo apresenta resultados parciais do desenvolvimento de atuações educativas de êxito na cidade de Goiânia, por meio do Programa Institucional de Bolsas de Iniciação à Docência, do curso de Pedagogia da Faculdade de Educação da Universidade Federal de Goiás. Tais atuações são práticas referendadas pela comunidade científica internacional, indicadas na organização da proposta Comunidades de Aprendizagem, que são desenvolvidas em escolas. O que se apresenta no texto são indicativos do impacto dessas atuações em duas escolas da rede municipal de Goiânia, sob a ótica de bolsistas do programa Pibid (estudantes da Pedagogia e professoras da educação básica), e também de crianças, tendo como referência a aprendizagem dos estudantes das escolas envolvidas. A partir de princípios da Metodologia Comunicativa Crítica, o estudo apresenta dados levantados a partir de registros do acompanhamento do programa e de entrevistas realizadas com crianças e professoras das escolas. Os dados revelam que as atuações são vistas como positivas pelos sujeitos envolvidos, embora haja críticas e problematizações quanto a algumas dinâmicas e formatos, assim como com relação à dificuldade de desenvolvimento pleno das atividades. A análise aponta para uma inovação no que diz respeito à junção da aprendizagem instrumental com a vivência do diálogo na escola.

Palavras-chave: atuações educativas de êxito; comunidades de aprendizagem; aprendizagem dialógica; pibid; educação básica

Successful educational performances in Goiânia-GO: contributions to basic education through PIBID

\footnotetext{
Doutora em Educação pela Faculdade de Educação da Universidade Federal de Goiás. Professora adjunto da Universidade Federal de Goiás. E-mail: keilamatida@gmail.com

** Doutora em Educação Matemática pela Universidade Estadual Paulista Júlio de Mesquita Filho. Professora Adjunta da Universidade Federal de Goiás - UFG. E-mail: fatofeno@gmail.com

*** Doutora em Educação pela Universidade Federal de São Carlos. Professora Adjunta da Universidade Federal de Goiás - UFG. E-mail: vanessagabassa@gmail.com
} 


\begin{abstract}
The article presents partial results of the development of educational activities of success in the city of Goiânia, through the Institutional Scholarship Program Introduction to Teaching, of Faculty of Education, of the Federal University of Goiás. Such actions are endorsed by the international scientific community practices listed in the organization of the proposed Learning Communities, which are developed in schools. What is presented in the text are indicative of the impact of these actions in two municipal schools of Goiania, from the perspective of fellows Pibid program (students of Pedagogy and teachers of basic education), and also of children, with reference to learning the students of the schools involved. From principles of Communicative Critical Methodology, the study presents data collected from program monitoring records and interviews with children and teachers in schools. The data show that the actions are seen as positive by the subjects involved, although there is criticism and problematizations as some dynamic and formats, as well as with respect to the difficulty of full development of the activities. The analysis indicates an innovation with respect to the junction with the instrumental learning experience with school dialogue.

Keywords: educational performances of success; learning communities; dialogic learning; pibid; basic education
\end{abstract}

O presente artigo trata da experiência das atuações educativas de êxito desenvolvidas em Goiânia-GO por meio do Programa Institucional de Bolsas de Iniciação à Docência (Pibid). Tal experiência se insere no âmbito do projeto Comunidades de Aprendizagem, desenvolvido em duas escolas municipais da cidade de Goiânia, desde 2014, em parceria com o Curso de Pedagogia da Faculdade de Educação-UFG.

O Pibid é uma iniciativa para o aperfeiçoamento e a valorização da formação de professores para a educação básica. Trata-se de um programa do governo federal que concede bolsas a alunos de licenciatura participantes de projetos de iniciação à docência desenvolvidos por Instituições de Educação Superior em parceria com escolas de educação básica da rede pública de ensino. O curso de Pedagogia da Faculdade de Educação-UFG elencou como seu projeto-Pibid a proposta Comunidades de aprendizagem, que passou a ser desenvolvida em duas escolas da rede municipal de ensino de Goiânia a partir de 2014.

\title{
1. Comunidades de Aprendizagem e Atuações Educativas de Êxito
}

Comunidades de aprendizagem é uma proposta educativa que se baseia em um modelo comunitário de escola, oriunda de experiências realizadas em países da Europa e da América do Norte. Nasceu na Espanha em 1995 e foi elaborada pelo Centro Especial de Investigação em Teorias e Práticas Superadoras de Desigualdades (Crea), 
da Universidade de Barcelona. Tal proposta implica a participação direta da comunidade na escola, acreditando que não é apenas o professor quem tem responsabilidade sobre o aprendizado dos estudantes, mas toda a comunidade de entorno da escola.

Trata-se de uma proposta educativa nascida como resposta às mudanças sociais que foram produzidas especialmente a partir da década de 1980, as quais engendraram a chamada Sociedade da Informação (CASTELLS, 1999). Esse novo contexto, baseado nas capacidades intelectuais dos sujeitos, na habilidade de seleção e processamento da informação, aponta novas demandas de formação para a escola e o acesso aos conhecimentos escolares, nessa nova realidade, torna-se elemento de proteção social e mecanismo de acesso a outros direitos fundamentais. Segundo Elboj et al. (2002), na proposta de Comunidades de aprendizagem parte-se do direito que todas e cada uma das crianças têm à melhor educação e se aposta em suas capacidades, contando com toda a comunidade educativa para se alcançar esse objetivo.

No Brasil, as Comunidades de aprendizagem começaram a ser desenvolvidas pelo Núcleo de Investigação e Ação Social e Educativa (Niase), da Universidade Federal de São Carlos, em 2002, mas hoje há outros grupos e instituições que trabalham em sua difusão no país e na América Latina. Em Goiás o projeto foi apresentado pela primeira vez em 2014, na cidade de Goiânia, por meio do Pibid, com o objetivo de possibilitar aos estudantes da Pedagogia uma formação docente ampla e ancorada em um modelo comunitário de escola, e também impactar positivamente os processos de ensino e de aprendizagem da educação básica.

A perspectiva de Comunidades de aprendizagem é ancorada pelo conceito de aprendizagem dialógica, que foi formulado pelo Crea-UB com base nos pressupostos teóricos de Habermas (agir comunicativo) e Freire (dialogicidade). A aprendizagem dialógica é entendida como: "[...] um conceito que diz respeito a uma maneira de conceber a aprendizagem e as interações. É formada por princípios que se articulam nas formulações teóricas para permitir descrever o que, na prática, se dá como uma unidade". (MELLO; GABASSA; BRAGA, 2012, p. 43). Tal conceito é composto por sete princípios.

O primeiro princípio é o diálogo igualitário, que pressupõe disposição para dialogar e compromisso com o estabelecimento de relações mais horizontais e verdadeiras. O diálogo igualitário busca promover uma sociedade mais justa, valorizando os seres humanos no seu modo de saber e entender o mundo. O que importa, a partir dessa perspectiva de diálogo, é o argumento que se está apresentando e não o lugar que ocupa quem está falando. Na escola, portanto, devem ser igualmente valorizadas as contribuições da diretora, da professora, da merendeira e do familiar daquela comunidade, em prol de uma educação de qualidade para as crianças. Dialoga-se sempre a 
partir de um objetivo comum, que é a melhoria da aprendizagem das crianças, jovens e adultos que estudam na escola, assim como o fomento de uma convivência respeitosa entre eles e elas.

O segundo princípio é o da inteligência cultural que, segundo Mello, Gabassa e Braga (2012), reconhece a inteligência como um processo intersubjetivo, originária das experiências de vida dos sujeitos nos seus contextos imediatos e sempre localizados em grupos e culturas. Para as autoras, a inteligência cultural de cada pessoa, de cada grupo deve ser valorizada, entendendo que cada uma delas com a bagagem cultural que possui tem algo a ensinar e o que ela sabe é válido para o lugar em que convive. Essa perspectiva abre novas possibilidades para a escola, pois, a partir dela, todos podem ensinar e aprender coisas e, portanto, todos podem participar ativamente da construção de uma escola de qualidade para crianças, jovens e adultos.

O terceiro princípio é o da transformação: efetivação dos dois anteriores. Trabalhando a partir do diálogo igualitário e da inteligência cultural, a escola não vai prender-se à reprodução da sociedade, mas sim às possibilidades de sua transformação. $\mathrm{O}$ impacto das mudanças acontece em âmbito individual e também coletivo, uma vez que a vivência dialógica permite reconstruir as relações interpessoais e institucionais.

O quarto princípio é o da dimensão instrumental da aprendizagem, que consiste na garantia de dominar todos os instrumentos necessários para uma vida digna na sociedade da informação, como: leitura e escrita de excelência, idiomas, informática, conceitos matemáticos, habilidades comunicativas, instrumentos esses que possibilitarão inserção e luta no mundo atual. Já o quinto princípio define-se pela criação de sentido, entendido como possibilidade de sentir-se protagonista da própria existência. Situação que implica em tomada de decisões, respeito ao outro, diálogo e interação (MELLO; GABASSA; BRAGA, 2012).

O sexto princípio é o da solidariedade, entendida, segundo as autoras, como elo que mantém os sujeitos conectados num pertencimento ao mesmo mundo social. A ação comunicativa e o diálogo dependem dessa solidariedade para se estabelecerem e, ao mesmo tempo, se engendrarem. Além disso, o fomento da solidariedade entre os sujeitos e a possibilidade de organizar a escola em torno de uma rede solidária de aprendizagem, que envolva o bairro e a comunidade como um todo aumentam as possibilidades de êxito educativo para todos. E o sétimo princípio é o da igualdade de diferenças. Esse princípio significa que o sujeito tem o igual direito de ser diferente. As pessoas podem dialogar mesmo com diferenças, respeitando-as.

Ao aderir à proposta de Comunidades de aprendizagem, uma escola dá início a um plano de ação que inclui diversas atividades pensadas para impulsionar a apren- 
dizagem dos estudantes. A partir de pesquisas de âmbito internacional (Strategies for inclusion and social cohesion in Europe from education: 2006-2011), elencou-se em Comunidades de aprendizagem um conjunto de atuações educativas de êxito, isto é, de práticas pedagógicas que, reconhecidas pela comunidade científica internacional, alcançam bons resultados em contextos diversos. As atuações educativas de êxito incluem: tertúlias dialógicas, grupos interativos, biblioteca tutorada, formação de familiares, modelo dialógico de resolução de conflitos e participação educativa da comunidade. São atividades realizadas dentro e fora da sala de aula, com estudantes e pessoas da comunidade de entorno.

Uma escola pode optar também pelo desenvolvimento de várias atuações educativas de êxito, ainda que não se transforme em uma Comunidade de aprendizagem. Na cidade de Goiânia foi essa a opção das escolas. Nas práticas iniciadas no âmbito do Pibid, temos desenvolvido fundamentalmente quatro atuações educativas de êxito: a biblioteca tutorada, a tertúlia literária dialógica; os grupos interativos; e a formação de familiares, a partir das quais os bolsistas de iniciação à docência do Pibid (estudantes do curso de Pedagogia) e a comunidade de entorno das escolas têm atuado.

\subsection{Biblioteca Tutorada}

Para Melo, Gabassa e Braga (2012), a biblioteca tutorada é um espaço aberto que potencializa as interações de quem dela participa (professores, voluntários, estudantes, familiares, bibliotecários dentre outros) e valoriza o conhecimento de cada um, uma vez que se sustenta sob a base teórica do diálogo igualitário, compreendido como um diálogo em que há um respeito mútuo entre os indivíduos participantes, independentemente de sua classe social, nível cultural, raça, credo ou faixa etária. Para que um diálogo seja considerado igualitário, faz-se necessária a contribuição de todos os envolvidos.

As autoras argumentam que a biblioteca tutorada fundamenta-se em Vigotski, para dizer que é no diálogo, nas relações com os outros que é possível aprender. Para esse teórico, a aprendizagem ocorre na relação que a criança estabelece com um adulto que possui maior conhecimento que ela. É no exercício do aprender junto que a criança desenvolverá autonomia para caminhar sozinha. Zona de desenvolvimento proximal e zona de desenvolvimento real evidenciam formas de lidar com o conhecimento vivenciado na escola.

No caso da biblioteca tutorada, esse conhecimento não se limita ao âmbito da sala de aula, ele se expande para fora dela. Por isso, a biblioteca pode (e deve) ser aberta em horários inclusive não regulares. Nela atuações podem ser desenvolvidas aten- 
dendo as demandas da escola. Nas experiências com as escolas de atuação do projeto em Goiânia, uma das necessidades é a alfabetização de crianças. Oficinas de leitura e escrita e apreensão do código linguístico estão sendo, para isso, desenvolvidas, assim como oficinas de contação de histórias.

A biblioteca tutorada é entendida nessa proposta como um espaço que potencializa o saber em vários aspectos e que pode potencializar a aprendizagem ao se constituir como uma ampliação do horário de atendimento ao aluno, para além da aula regular. No entanto, para que o trabalho com a biblioteca tutorada seja efetivado é necessária uma mobilização e conscientização da importância dela para a escola e a comunidade, como um espaço que pode potencializar a aprendizagem de todos, adultos e crianças e que, para isso pode contar com a participação de pessoas voluntárias (familiares dos estudantes, pessoas da comunidade, estudantes da universidade) para acompanhamento e realização de atividades diversas.

\subsection{Tertúlia Literária Dialógica}

Trata-se de uma nova organização da atividade de leitura, caracterizada pela interação social entre as pessoas mediada pela linguagem. Esta atividade é caracterizada não apenas pelo processo de leitura em si, mas pelo diálogo em torno das obras de literatura clássica, momento em que as pessoas podem trocar experiências, aprender conjuntamente e produzir mais conhecimento. Além disso, tal processo acarreta a produção de novos significados que transformam a linguagem e o conteúdo da vida das pessoas envolvidas.

A gênese dessa atividade foi decorrente da experiência em uma escola de pessoas adultas da cidade de Barcelona:

[...] a atividade é atualmente difundida pela Confederação de Federações e Associações de Participantes em Educação e Cultura Democrática de pessoas Adultas (CONFAPEA), da Espanha, por meio do projeto "Mil y Uma Tertúlias Dialógicas por Todo El Mundo". A ideia é tomar a leitura como território de união de diferentes conhecimentos (os do mundo da vida e os do sistema), caminho construído entre homens e mulheres de diferentes idades, formação, procedência e etnias. (MELLO, 2003, p. 450).

O conceito da leitura dialógica, concretizado na prática de Tertúlia Literária Dialógica faz parte de uma concepção de aprendizagem dialógica, já descrita anteriormente, e significa um processo intersubjetivo de ler e compreender um texto, aprofun- 
dar, refletir criticamente sobre o texto e o contexto, dessa forma a compreensão leitora através da interação com outros agentes abre as possibilidades de transformação como pessoa leitora e como pessoa no mundo (VALLS, SOLER ; FLECHA, 2008).

A tertúlia literária dialógica consiste na construção coletiva de sentidos com base no diálogo oriundo da leitura de uma obra da literatura clássica. Mas a tertúlia pode ser também voltada para o campo das artes, da música, da pintura, da ciência etc. Valoriza-se, nessa atuação, o contato com saberes legitimados. Mello (2003) afirma que na tertúlia literária não se pretende analisar o que o autor ou a autora de uma obra propõe, mas valorizar as várias e possíveis interpretações do grupo sobre, por exemplo, o texto lido. Ela afirma que:

\begin{abstract}
A Tertúlia Literária Dialógica é uma atividade educativa desenvolvida a partir da leitura de livros da literatura clássica universal. A atividade está baseada no diálogo como gerador de aprendizagem. Não apresenta nenhum obstáculo social ou cultural para a participação: é uma atividade gratuita aberta a todas as pessoas, de diferentes coletivos sociais e culturais, inclusive às pessoas que recém aprenderam a ler. (MELLO, 2003, p. 450).
\end{abstract}

No Brasil, essa atuação tem sido objeto de pesquisa de Girotto (2007). A autora apresenta práticas com a tertúlia literária dialógica com crianças e adolescentes situados em uma periferia de São Carlos, no interior de São Paulo. As atividades são iniciadas com a leitura de clássicos literários visando permitir que crianças, de diferentes faixas etárias e níveis escolares, possam ter acesso a esse tipo de obra. Suas pesquisas revelam que a tertúlia não é só uma atividade de leitura, uma vez que promove a transformação pessoal dos participantes. A autora afirma que a efetivação da tertúlia resulta num espaço de humanização, pois nessa atividade as diferenças se completam, situação que enriquece o modo de compreender a vida e o mundo.

Girotto (2007) ressalta também a importância da literatura na vida das crianças e dos adolescentes e o modo como cada indivíduo realiza uma interpretação pessoal com a obra literária escolhida previamente e em conjunto com o grupo. Os participantes relacionam as obras escolhidas com a realidade em que vivem. A literatura clássica universal passa a ser disposta a todos os alunos, independente da classe social ou do nível de instrução escolar a que pertencem.

Ao centrar-se na prática de leitura, a atividade de Tertúlia Literária Dialógica "prevê a necessidade de se dedicar um tempo considerável para repassar palavras, letras, sons, praticar diversos exercícios que reforcem aquilo no que a criança apresenta maior dificuldade" (ELBOJ, et al., 2002, p. 115). 
Nesse sentido, a presença de uma pessoa mais experiente para mediar a atividade é essencial no processo de concretização de tal dinâmica, que segue, em geral, os princípios da aprendizagem dialógica, ou seja, o moderador tem a função de garantir que todos os princípios sejam efetivados com êxito, de maneira a se conseguir mais aprendizagem.

As pessoas participantes dessa atividade decidem a obra de literatura a ser lida conjuntamente, selecionam trechos, parágrafos ou capítulos do livro e durante o encontro falam a respeito do que sentiram, pensaram, entenderam sobre aquele excerto. O importante é que os argumentos sejam ouvidos e respeitados e as pessoas façam conexão com a vida e com temas da atualidade, sempre no sentido de aportar elementos positivos na construção da aprendizagem intersubjetiva. O papel do moderador é garantir que todas as falas sejam respeitadas seguindo a orientação da aprendizagem dialógica. Esta pessoa pode ser a professora da sala, uma criança mais experiente ou um adulto da comunidade.

Com duração de em média, uma a duas horas semanal (is), na Tertúlia Literária a leitura dos clássicos universais é central, por serem comprovadamente obras que possibilitam maior profundidade nas discussões sobre temas inerentes ao ser humano, como o amor, pobreza, fome etc. por sua qualidade, universalidade e atestado de permanência. Por esse motivo se aposta que tal literatura deve estar ao alcance de todas as pessoas, independente de sua classe social, garantindo as mesmas possibilidades de oportunidades a todas e todos.

No trabalho que temos desenvolvido no cidade de Goiânia, as tertúlias vêm conquistando as professoras das escolas como possibilidade de avanço para as crianças e, nessa direção, tem sido realizadas no âmbito da sala de aula, com periodicidade semanal. A atividade também tem acontecido em instituições parceiras das escolas atendidas, como é o caso de u ma escola de circo da cidade que, ao atender as crianças de uma das escolas envolvidas no projeto, tem desenvolvido a tertúlia com diferentes grupos de crianças e adolescentes, no contra turno ao horário da aula regular. Nesse artigo, porém, serão apresentados os dados relativos a apenas uma das escolas envolvidas com a tertúlia.

\subsection{Grupos Interativos}

Trata-se de uma proposta educativa que visa uma reorganização do trabalho pedagógico em sala de aula. Consiste em redimensionar o espaço e tempo do trabalho em sala de aula. Para tanto, é necessário organizar os alunos em pequenos grupos 
heterogêneos (em média cinco ou seis alunos por grupo). É uma prática pedagógica que contribui para a superação do fracasso escolar, pois, desencadeia, por meio das interações sociais estabelecidas em sala, a aceleração da aprendizagem das crianças.

O planejamento dos conteúdos trabalhados é desenvolvido pelo professor de cada turma. É o professor quem elabora as atividades que serão desenvolvidas em classe. As atividades devem ser curtas, pensadas num tempo comum em que os alunos da sala consigam realizar estas atividades propostas. É importante frisar que os conteúdos abordados para a realização da atividade não podem ser conteúdos novos, eles devem sempre ter sido bem trabalhados anteriormente pela professora ou professor da classe. Essas atividades devem abordar conteúdos já vistos pelos alunos, no intuito de reforçar, fixar o conhecimento já ensinado/aprendido pelos estudantes (ELBOJ et al., 2002, p. 93)

Porém, dentro desta prática pedagógica, não é só o professor ou a professora a única pessoa responsável por dinamizar o trabalho pedagógico. Tal proposta conta com o apoio de mais pessoas na sala de aula para garantir o atendimento mais direto com cada criança, para ajudar a esclarecer melhor os conteúdos trabalhados e também garantir o respeito entre todos no grupo. A participação de pessoas voluntárias (professores, familiares e outros agentes educativos: estagiárias de graduação, funcionários da escola, pessoas da comunidade etc.) dentro da aula, é extremamente importante pois, em colaboração com o professor da turma possibilita o aumento do rendimento escolar dos alunos. Quanto mais variado for este grupo de voluntários, mais rica será a interação e maior serão as chances para que ocorra aprendizagem dos alunos (ELBOJ, 2001).

O voluntário mediador auxilia os alunos nas atividades propostas pelo professor. Desse modo, o professor deixa de ser o único responsável pelo aprendizado dos alunos, que aprendem na interação com o diferente, já que é importante e necessário, para isso, compor grupos cada vez mais heterogêneos. De acordo com Yeste (2004, $\mathrm{s} / \mathrm{p})$ :

Os grupos interativos são uma transformação da organização de uma aula, onde se formam pequenos grupos heterogêneos, sob critérios de rendimento, etnia, gênero, etc. Nos grupos, com o apoio de uma pessoa adulta (familiar, voluntário ou outro profissional, que é a dinamizadora do grupo, se trabalham atividades curtas sobre um tema comum, e se organiza o tempo de maneira que todos os grupos de meninas e meninos realizem quatro atividades (ou cinco, dependendo do número de alunos). 
O mediador tem a função de promover o diálogo entre o grupo de alunos, de garantir que a atividade seja efetivada coletivamente e não individualmente. $\mathrm{O}$ conhecimento alheio permite, pois, a partilha e o aprendizado. Ao professor cabe a responsabilidade de percorrer os grupos tirando dúvidas, coordenando-os. Essa dinâmica permite "trabalhar valores como a solidariedade e o respeito por um lado, e habilidades sociais como o trabalho em equipe, a iniciativa, a autoestima e as habilidades comunicativas por outro" (YESTE, 2004, s/p.).

Em cada grupo se realiza uma atividade diferente, mesmo que estejam relacionadas com o mesmo tema ou assunto. $\mathrm{O}$ tempo total desta dinâmica se divide pelo número total de grupos interativos. Por exemplo, se houver na sala três grupos formados, em um espaço de uma hora, cada atividade durará 20 minutos. Transcorrido esse tempo, muda-se a atividade. A combinação da mudança da atividade fica a critério do professor. Tanto a pessoa moderadora da atividade pode se dirigir com a atividade em mãos, ou ao invés disso, o grupo pode passar de maneira rotativa a cada vinte minutos pelas atividades.

Em Goiânia-GO temos desenvolvido grupos interativos de duas maneiras: há turmas de anos iniciais que são coordenadas por professores polivalentes que realizam a atividade com o apoio dos bolsistas do Pibid envolvendo as várias áreas de conhecimento que o professor trabalha em aula e há turmas com professores específicos que desenvolvem grupos interativos a partir das disciplinas ministradas por eles, como é o caso da Matemática.

\subsection{Formação de Familiares}

Em Comunidades de Aprendizagem, a escola caracteriza-se por ser eixo educativo de toda a comunidade, contribuindo na sua própria formação. Por isso, os familiares devem ir para a escola tanto para participar de decisões e processos educativos de seus filhos e demais estudantes, como também para, eles próprios, desfrutarem de novas aprendizagens (alfabetização, tertúlias, informática, artesanato etc) (MELLO; BRAGA ; GABASSA, 2012).

Essa abertura da escola para a formação de familiares, em temas que eles escolhem aprender, é considerada central por três motivos:

[...] a) a visão comunitária da proposta entende todos os sujeitos de uma comunidade em relação, dessa forma, ao se dedicar a novas aprendizagens, b) os familiares potencializarão diretamente as aprendizagens dos seus 
filhos e filhas; o sentido dado à escola como lugar próprio daquela comunidade aumenta os laços de confiança e, portanto, as possibilidades de efetiva participação da comunidade na vida da escola e c) a permanente formação dos adultos daquele local fortalecem suas possibilidades de sustento e busca de melhoria de condições de vida e trabalho. (MELLO; BRAGA ; GABASSA, 2012, p. 127)

Nessa ação, a aprendizagem das crianças e de toda a comunidade é fortalecida. Em nosso projeto na cidade de Goiânia temos desenvolvido uma atividade relacionada à formação de familiares, a oficina de informática. Em uma das escolas em que o projeto acontece, uma vez por semana, no período vespertino, pais participam de curso de informática básica, aprendendo assim a lidar com o computador, ligá-lo e desligá-lo, a manusear o mouse, procurar e baixar vídeos, pesquisar na internet, enviar e-mail etc. Com isso, podem inclusive ajudar os filhos nas atividades escolares, bem como participar de uma realidade cujo conhecimento exige esse tipo de interação ofertada pela tecnologia.

\section{Objetivos e Método}

Paralelamente ao acompanhamento do Pibid-Pedagogia temos também desenvolvido um projeto de pesquisa a partir das atuações educativas de êxito que temos realizado nas escolas em Goiânia-GO. Tal projeto teve início no ano de 2015 e se estenderá até 2017, com financiamento do Conselho Nacional de Desenvolvimento Científico e Tecnológico. Neste ensaio apresentamos resultados parciais deste estudo.

O objetivo da pesquisa tem sido o de evidenciar o impacto do desenvolvimento de atuações educativas de êxito nas escolas, tanto para a formação de professores (inicial e continuada) como para a aprendizagem das crianças que estudam na educação básica.

Os dados que apresentaremos foram coletados a partir de princípios da Metodologia Comunicativa Crítica, isto é, com base na aprendizagem dialógica e na perspectiva de investigação que prevê um diálogo constante entre pesquisadores e sujeitos investigados. A coleta foi realizada da seguinte maneira: a) por meio do registro da participação de bolsistas do Pibid e outros profissionais das escolas nas reuniões de acompanhamento do Programa e no Seminário Aberto Comunidades de Aprendizagem, o qual se realiza quinzenalmente na Faculdade de Educação da UFG para possibilitar o estudo e a discussão da proposta Comunidades de Aprendizagem e seu 
referencial teórico; b) por meio da produção escrita, realizada também pelos bolsistas Pibid, de um relato sobre a participação no projeto; c) por meio do registro das atuações acompanhadas em fichas de observação e; d) por meio de relatos gravados em áudio dos próprios estudantes da educação básica, participantes das atuações educativas de êxito.

Em todos os casos, os dados que apresentamos neste momento se referem a uma análise parcial dos impactos das atuações educativas de êxito na aprendizagem das crianças do ponto de vista, sobretudo, dos bolsistas Pibid, isto é, estudantes do curso de Pedagogia e professoras supervisoras das escolas acompanhadas.

\section{Resultados Alcançados}

Os resultados alcançados com o desenvolvimento das atuações educativas de êxito dizem respeito, de maneira geral, ao aumento da motivação dos estudantes, ao crescente interesse pelos conteúdos de ensino que antes eram pouco valorizados, ao gosto pela aprendizagem compartilhada e pelo trabalho cooperativo e ao crescente clima de respeito, solidariedade e diálogo que foi sendo gestado pelas turmas envolvidas no trabalho. Mas há resultados mais específicos que remetem à particularidade das atuações educativas de êxito, assim como limitações e dificuldades que foram encontradas ao longo do percurso.

\subsection{Resultados da Biblioteca Tutorada}

No que diz respeito à Biblioteca Tutorada foram desenvolvidas, sobretudo, oficinas de contação de histórias, a partir das quais as bolsistas Pibid (estudantes da Pedagogia) preparavam histórias para serem lidas, dramatizadas e compartilhadas com as crianças. A atividade acontecia na biblioteca da escola, no horário regular da aula, pois não havia a possibilidade de realização no contraturno. $\mathrm{E}$ as turmas que tinham interesse reservavam um horário da semana para participar. $\mathrm{O}$ atendimento se deu especialmente para crianças de pré-escola (uma das escolas atendidas têm turmas de educação infantil) e de primeiro ano, com o objetivo de auxiliar diretamente no processo de alfabetização.

As crianças participantes são unânimes em dizer que a atuação é positiva. "Eu gosto de tudo... das histórias, das professoras, das tarefas, das leituras, de desenhar e de escrever. " (estudante $-1^{\circ}$ ano). Outro comenta o quanto se sente motivado: 
"Eu gosto das leituras porque eu quero aprender a ler muito. " Em todos os casos as crianças demonstram sua empolgação com a inovação que a atuação traz para a escola.

As professoras das turmas envolvidas também veem de maneira positiva o envolvimento de seus alunos e a possibilidade de participarem do projeto.

A minha turma é uma turminha A (primeiro ano), participou da contação de história. É um momento que eles gostam muito. Eles participam bem. Quando eles vão para a sala, recontam para a sala, é um trabalho que eu já vinha desenvolvendo com eles também. É um momento muito válido para eles, onde eles soltam a imaginação. Que eles se divertem, participam no reconto na sala. Isso nos ajuda no processo de alfabetização. Então está sendo um trabalho muito válido.

Vale destacar, porém, que essa atuação tem a limitação de ser desenvolvida no horário regular da aula, quando deveria, como aponta a teoria do projeto, ser realizada como um espaço a mais de aprendizagem para as crianças, para além da sala de aula (MELLO, BRAGA e GABASSA, 2012.). Certamente o impacto com relação à aprendizagem dos estudantes poderia ser maior se a atuação não tivesse que "competir" com a aula das professoras. Apesar das avaliações positivas, consideramos essa uma discussão fundamental para o âmbito da gestão da escola e da organização do trabalho pedagógico.

\subsection{Resultados da Tertúlia Literária Dialógica}

No caso da Tertúlia Literária Dialógica, a coleta de dados em uma das escolas participantes se efetivou nos meses de novembro e dezembro de 2015 a partir tanto de fichas de observações quanto de entrevistas com os alunos da primeira fase do ensino fundamental participantes do projeto. Essa atuação acontecia no espaço da biblioteca escolar. Desse modo, em horários determinados os alunos eram encaminhados à biblioteca para realização da tertúlia.

Na efetivação dessa atuação, se em determinados encontros a tertúlia era conduzida por bolsistas da universidade, no caso os pibidianos, em outros ela também contava com a participação dos alunos. Muitas vezes os alunos faziam as inscrições e a memória dessa atuação de êxito. Foi possível perceber que os princípios da aprendizagem dialógica se realizavam nesses momentos, como, por exemplo, o caso de um aluno que vendo o nervosismo do outro em relação à leitura de um trecho o ampara dizendo: "Eu leio sua parte e depois você comenta" (Pedro, 2015). Desse modo, nessa e 
em outras situações, foi possível perceber que a aprendizagem não ocorria de maneira individual, havia uma preocupação com o outro, e, portanto, um compromisso em ajudá-lo.

Falas das crianças mostraram a importância da leitura partilhada e o papel da literatura na relação leitor-mundo:

"Hoje não daria para viver o sonho como Dom Quixote viveu porque as pessoas não têm mais o coração tão bom como as pessoas que Dom Quixote teve como amigo" (Hania, 2015).

“Tia, isso também acontece na vida da gente, quando a gente compra uma bicicleta nova o outro quer ser amigo da gente só por causa da bicicleta" (Vitor, 2015).

A discussão ocorrida nessas falas era do livro Dom Quixote, adaptado por Ana Maria Machado, rememorado em momento de entrevista com os alunos:

"Eu gostei mais porque o Dom Quixote gostava muito de ler, até que ele ficou doido pela leitura, ficou imaginando coisas" (João, 2015).

"Ele imaginava um monte de coisas, até usava uma bacia na cabeça" (Ana, 2015).

Isso mostra a relação que os alunos estabeleceram com os livros, elegendo-os como bons livros inclusive: “...o livro era muito bom, nós aprendemos muitas coisas" (João, 2015). Outros sentidos de leitura foram construídos por outros títulos lidos, como a Pedra da Sabedoria, de Hans Christian Andersen, contos de Marina Colasanti e Tampinha, de Ângela Lago:

"Na história da Pedra da Sabedoria tinha um sábio homem que tinha também os filhos sábios, um tinha o paladar melhor, mas esqueci os nomes, cada um tinha uma boa característica, uma espécie de sabedoria, sabiam muitas cosias boas e diferentes, dentre seus filhos uma era cega, no entanto, ela sabia muita coisa: era mais inteligente que seus irmãos, mas menos sábia que o sábio da pedra da sabedoria" (Luiz, 2015).

"Foi que a mulher tentava fazer um marido para ela, para que ela não vivesse mais só, como se fosse um marido para ela, eu achei interessante" (Mara, 2015). 


\begin{abstract}
"Umas das histórias que eu li achei interessante que me ensinou algo assim: que nossa eu quero isso porque isso é bom, porque eu quero, e depois se vai enjoando, vai enjoando até não querer mais nada, e é interessante que nem tudo que queremos podemos ter" (Carlos, 2015).

“Tampinha era uma menina pequena que quis fazer algo por alguém, o Bonito. Por ele, ela enfrentou muitas coisas como cobra, por exemplo, mas ela não desistiu hora nenhuma de encontrar a flor para fazer o chá para $o$ Bonito. Eu gostei porque esta história nos faz pensar em ter perseverança, em não desistir quando tudo parece difícil” (Marta, 2015).
\end{abstract}

A relação leitor-mundo como troca, como partilha contribui para a formação do leitor e do escritor. De modo semelhante foi possível observar, pela fala das crianças, o que tais práticas acarretaram tanto em relação à prática da leitura, à ampliação vocabular da língua, como ao próprio funcionamento da tertúlia:

“[...] Eu tinha dificuldade em ler, com o tempo foi passando, e com a tertúlia eu leio melhor. [...] Eu gostei da tertúlia porque trouxe muita coisa, me ajudou a ler melhor" (Luiz, 2015).

"Eu achei bom termos tertúlia porque ela nos ajudou a ler melhor, a aprender, a saber a hora certa de falar e a hora certa de escutar" (Carlos, 2015).

"Desgraçado é algo sem graça, sem graça. Nesse caso, estava tão ruim tudo e ainda colocaram pimenta" (Pedro, 2015).

"Aprendemos a levantar a mão para poder falar, tinha aqui na biblioteca vários cartazes que estavam falando sobre atitudes de respeito e educação" (Marcos, 2015).

A tertúlia permite, desse modo, o aprendizado escolar não circunscrito ao espaço da escola ao mesmo tempo que possibilita entender uma dinâmica fundamentada no respeito, na igualdade, na valorização das diferenças culturais. É claro que esse processo não ocorria sem conflitos, muito menos com compreensão exata, como mostram as falas a seguir:

"Na hora que tiver lendo não ficar conversando porque os meninos ficam conversando a hora que algumas pessoas estão lendo" (Clara, 2015).

"Não é mudar, é acrescentar. Por exemplo, a tia algumas vezes deixa algu- 
mas meninas anotar, fazer as inscrições, faz dar briga. No grupo da tertúlia alguns meninos vão duas vezes, outro vai só uma, então, cada dia ser uma pessoa diferente" (João, 2015).

As fichas de observação relatam ainda conversas paralelas, leituras em determinados dias feitas de maneira superficial, ausência de compromisso das crianças com a proposta, tal como aponta a fala da professora:

"Parece que esses conteúdos são assim desconhecidos para os alunos, parece assim que eles não têm essa tendência de pensar na vida como algo complexo não, só pensam no aqui e no agora, sem medir consequência, porque vocês não estão conseguindo contribuir, estou vendo que tem gente aqui levando tudo na brincadeira. Isso é uma oportunidade de crescimento intelectual. Possibilidade de pensar a vida a partir de um conto, de uma fábula, isso para a vida. Para vocês darem um encaminhamento correto e não para levar a vida de qualquer jeito" (Professora, 2015).

O desabafo da professora como forma de chamar atenção dos alunos mostra que a tertúlia não se realiza de maneira harmônica justamente porque a aprendizagem dialógica não se concretiza de repente. É pelo convívio, pelo dizer diário, pela reflexão conjunta que alunos e professores vão participando melhor desse momento de partilha, com avanços e retrocessos típicos de qualquer aprendizagem humana.

\subsection{Resultados dos Grupos Interativos}

Nos grupos interativos com vista ao estudo da matemática, percebeu-se por parte do grupo de pidibianos, supervisores e coordenador o desejo de não somente "reforçar, fixar o conhecimento já ensinado/aprendido pelos estudantes" tal como propões Elboj et al (2002, p. 93). O grupo parte da compreensão de que aprende-se matemática pensando e compartilhando modos de compreender e resolver situações problemas. Assim, as situações não eram uma mera repetição de questões trabalhada em sala, embora isto também pudesse ocorrer. É que uma situação problema em matemática assim é compreendida se não se sabe como resolvê-la, mas se busca modos de solução a partir de conhecimentos já adquiridos e também com busca de informações que possibilitem resolvê-la. Partindo desta compreensão, as atividades com ideias e conceito matemáticos eram explorados com o apoio dos voluntários e bolsistas que recebiam uma formação na qual eram orientados a incentivar modos diversos de pen- 
samento e ainda eram orientados a apresentar possibilidades de soluções e deste modo promover a revisão do compreendido com o intuito de complexificá-lo.

As atividades resolvidas durante os grupos interativos de matemática envolviam questões que retomavam conceitos explorados em sala por meio de situações problemas e por meio de jogos que eram problematizados em seu conteúdo aproximando os alunos da linguagem simbólica da matemática. Em todas as atividades era disponibilizado aos grupos materiais didáticos que possibitassem rever e construir, a partir da observação empírica de fenômenos matemáticos, regularidades numéricas que contribuem para processos operatórios.

Durante as vivências o grupo de professores e bolsistas realizaram adaptações com relação à dinâmica do grupo interativo, deixando o tempo da atividade seguir o tempo do envolvimento e do esforço na solução dos problemas apresentados. Os grupos tinham a liberdade de escolher quando mudar de atividades, visto que conforme a compreensão de uma matemática para o pensar (VILA; CALEJO, 2006), não se pode prever o tempo da criatividade de elaboração de conjecturas e compartilhamento e refutação de ideias. Mesmo tendo o grupo um tempo indeterminado para a realização das atividades, havia por parte do coordenador do grupo a orientação de que o grupo tentasse, com todo a sua dedicação, resolver todas as atividades propostas para o dia (período de 1h30) e quando não o conseguia os motivos eram apresentados e avaliados ao final do período. Deste modo, podia-se refletir com os alunos sobre o empenho, colaboração ou dispersão durante a atividade matemática e seus efeitos na aprendizagem.

Embora se perceba que os alunos tiveram a oportunidade de rever compreensões e modos de agir em sala de aula, a vivência de alguns princípios da aprendizagem dialógica, tal como solidariedade e respeito pela diversidade de modos e tempo de aprender ainda se mantém como um desejo. Podemos atribuir isto ao fato de não se ter instalado uma comunidade de aprendizagem nas escolas de modo que todos os envolvidos com a atividade escolar (professores, pais, alunos, servidores) pudessem expressar desejos e necessidade assumindo junto com a escola o compromisso de buscarem saídas para os problemas encontrados. Atitudes individuais não se mostram eficazes para a melhoria das relações e qualidade do trabalho na escola. Houve ainda, por parte dos professores um receio de deixar grupos de alunos sendo acompanhados por voluntários, que sem uma formação pedagógica sólida, poderiam não saber como lidar com conflitos e dificuldades dos alunos. Tal receio fez com que se tornasse regular e sistemática as reuniões para a formação e acompanhamento de voluntários.

Nos grupos interativos realizados em outras disciplinas das escolas, como o 
caso da língua portuguesa, tentou-se seguir exatamente a metodologia proposta pela teoria que embasa a proposta de Comunidades de aprendizagem. Nesses casos percebeu-se que houve, principalmente no início do desenvolvimento da atividade, uma preocupação recorrente com a questão do tempo limitado para cada exercício, o que fez os professores irem buscando alternativas e adequando suas propostas. Os estudantes se envolveram bastante com a atuação, embora momentos de conflito também tenham existido, especialmente no que diz respeito a ajudar o outro e a ter paciência com a aprendizagem do colega.

A motivação, sobretudo, aparece com destaque como resultado dessa atuação. "No grupo interativo a gente vê a alegria das crianças" (estudante, bolsista Pibid), assim como a questão da convivência com pessoas da comunidade como um fator de riqueza para a aprendizagem. "Uma avó foi ajudar e ela não sabia ler, mas queria ajudar, então foi ouvir a leitura das crianças" (professora supervisora Pibid). Ainda é possível destacar o fomento de um clima de diálogo, respeito e solidariedade, uma vez que todos se sentem responsáveis pela aprendizagem dos colegas nos grupos interativos. Mesmo que haja dificuldade ou que em alguns dias as crianças não alcancem esse propósito, no geral há mais respeito e solidariedade. "As crianças querem ajudar. Agora até mesmo sem ser no grupo interativo" (professora supervisora Pibid).

Por fim, vale apontar uma questão fundamental que surgiu no desenvolvimento dos grupos interativos, que é a questão dos alunos com defasagem de aprendizagem. Nesses casos, percebeu-se avanços, mas não tanto quanto seria necessário para alcançarmos uma situação de equidade. Nesses casos, avaliamos, em conjunto com os sujeitos da pesquisa e do projeto, que seriam necessárias outras frentes de atuação junto aos alunos, especialmente fora do horário regular da aula, para que tivessem mais possibilidades de aprendizagem.

\subsection{Resultados da Formação de Familiares e da comunidade em geral}

Uma das formas de desenvolvimento dessa atuação de êxito referiu-se à formação das pessoas voluntárias que foram para as escolas atuarem em atividades como a biblioteca tutorada, tertúlias literárias e grupos interativos. Em sua grande maioria esse grupo de voluntário era formado por estudantes da própria escola, da segunda fase do ensino fundamental, mães, irmãos e vizinhos ou ex-alunos das escolas.

Para que a comunidade pudesse atuar nas atividades foram realizados, mensalmente, encontros com os voluntários. Nestes encontros eram apresentados e discutidos os princípios da aprendizagem dialógica e retomados conteúdos escolares que 
seriam tratados durante o mês que se seguiria nos grupos interativos, por exemplo. Muitos dos voluntários eram alunos de séries mais avançadas da mesma escola e mães que tinham a possibilidade de rever suas próprias compreensões conceituais e modos de lidar com as dificuldades de seus colegas de escola e familiares.

Embora não tivessem a função de substituir o professor, o fato de compreenderem as questões apresentadas para a solução e as possibilidades de solução contribuiu para uma atuação em que se valoriza os modos de pensar e incentivo a sua exposição e compartilhamento com os pares. Além disso, contribui diretamente para que esses familiares e alunos ou vizinhos da escola tenham reforçada a aprendizagem instrumental desses conteúdos, $o$ que favorece a formação e emancipação da comunidade como um todo.

Outra maneira de desenvolvimento da formação de familiares se deu com a organização de um curso de informática voltado para estudantes da Educação de Jovens e Adultos de uma das escolas acompanhadas. Nesse caso, os estudantes aprendiam com uma bolsista Pibid e sua supervisora os conceitos básicos da informática (ligar e desligar o computador, usar o programa word), além de utilizarem os computadores para o próprio processo de alfabetização.

$\mathrm{Na}$ oficina percebemos que houve mais aprendizagem dos conhecimentos de informática: digitação, função das teclas, acentuação, pontuação, letra maiúscula. A aluna $\mathrm{G}$ não conseguia lembrar como era a letra $\mathrm{Q} / \mathrm{q}$; pediu ajuda à bolsista umas três vezes perguntando: "Como é o Q/q? - É o q do queijo?", depois conseguiu reconhecer a letra e encontra-la no teclado sozinha. (Supervisora Pibid)

Destaca-se também, assim como com as crianças, que o trabalho a partir dos princípios da aprendizagem dialógica tem ajudado a construir um trabalho mais solidário e coletivo entre os adultos.

Pudemos notar que as alunas procuram ajudar umas às outras, por exemplo, quando $\mathrm{Z}$ pediu ajuda à bolsista porque tinha esquecido como dar espaço entre as palavras, a colega $\mathrm{M}$ prontamente auxiliou $\mathrm{Z}$ ensinando como fazer. (Supervisora Pibid)

\section{Considerações}

O desenvolvimento de atuações educativas de êxito na cidade de Goiânia, em escolas da rede municipal de ensino, tem demonstrado inúmeros impactos positivos, 
especialmente no que diz respeito ao envolvimento e aprendizagem de conteúdos por parte dos estudantes da educação básica e a melhoria da convivência entre eles (mais diálogo, mais respeito e mais trabalho coletivo) como revelam, ainda que parcialmente, os dados desse estudo.

Esses dois elementos (aprendizagem e convivência) são justamente o fator de inovação da proposta Comunidades de aprendizagem e das atuações de êxito. Quanto a isso, a teoria que embasa o projeto revela que as atuações de êxito trabalham simultaneamente a aprendizagem instrumental e as interações entre os estudantes, por isso obtém bons resultados. "Las AEU conjugan el rigor académico com los procesos de colaboración en el aula favorecendo un aprendizaje que los mismos protagonistas califican de más profundo y motivante" (FLÉCHA et al, 2014).

A Biblioteca Tutorada e a formação de familiares, que acontecem em espaços diferentes da sala de aula regular, atraem a atenção e o interesse de adultos e crianças, especialmente porque fomentam o trabalho com instrumentos fundamentais para a vida na sociedade atual, como a leitura e os conhecimentos computacionais. Inovam na medida em que articulam esses instrumentos à convivência dialogada do grupo, ao saber ouvir e poder falar. As atuações, porque dialógicas, ganham maior valor diante de seus participantes.

A experiência vivenciada nas escolas parceiras em relação à tertúlia também mostra-se bastante significativa. Não apenas alunos conclamam para que essa realização seja permanente, mas os professores entrevistados alegam isso. A tertúlia como momento de leitura partilhada permite o aprendizado escolar do ato de ler não apenas limitado ao processo de decodificação porque o aluno precisará, sim, ler trechos do livro antes de comentá-lo, ou apontar palavras significativas, mas avança em relação a isso ao permitir o trânsito livro-mundo. Ler a palavra prenhe de mundo, como diz Paulo Freire (2015), é sustentáculo para essa proposta que se inicialmente aceita pela escola abre possibilidades para que o aluno adentre outros textos cuja mediação não se realiza na escola.

O aprendizado da leitura como momento de partilha a partir de dinâmica própria, que envolve ler, ouvir o outro, trocar experiências, levantar expectativas, sintetizar enquanto memória um certo momento faz dela prática diferenciada. Por isso, a tertúlia literária dialógica ganha espaço na escola e em outros lugares em que o convívio humano respeitoso faz-se necessário, como no circo Laheto. Esse respeito não supõe silenciamento, mas permissão para dizer, para ouvir o outro enquanto aprendiz de mundo.

O interesse dos estudantes pelos grupos interativos também não é diferente. 
Eles desejam, aguardam e reivindicam a realização da atividade em suas turmas. Gostam e se saem melhor trabalhando em grupo, diferente do que aprendemos no senso comum da escola. Têm muitas dificuldades em realizar de fato um trabalho colaborativo e solidário, comprometido com a aprendizagem de todos e não somente de si mesmos, mas se esforçam para isso, melhoram a cada aula e aprendem sobre a própria postura. E apesar das questões levantadas quanto o tempo estimado para a atividade e a organização dos conteúdos, compreendemos que os princípios são extremamente válidos e inovadores, na junção entre aprendizagem instrumental e diálogo.

Percebe-se, nessa análise, que é possível realizar atuações de êxito de forma isolada e obter-se bons resultados nas escolas, mas esses resultados seriam mais significativos se a proposta fosse tomada como a própria forma de organização da escola, isto é, como seu projeto político pedagógico. (MELLO et al, 2012). As atuações desarticuladas têm a limitação de seu tempo e espaço, e dos sujeitos que dela participam. Ainda assim as escolas envolvidas podem se valer dessa problematização para fazerem avançar seu desejo pela melhoria do ensino e da aprendizagem nas comunidades escolares.

\section{Referências}

ANDERSEN, H. C. A pedra da sabedoria. Adaptado por Ana Maria Machado. São Paulo: Global Editora, 2005.

CASTELLS, M. A sociedade em rede - a era da informação: economia, sociedade e cultura. Vol 1. $5^{\mathrm{a}}$ edição. São Paulo: Paz e Terra, 1999.

CERVANTES, M. Era uma vez Dom Quixote. Tradução Ana Maria Machado. São Paulo: Editora Global, 2005.

ELBOJ et al. Comunidades de aprendizaje. Transformar la educación. Espanha: Graó, 2002.

GIROTTO, V. C. Tertúlia literária dialógica entre crianças e adolescentes: conversando sobre âmbitos da vida. 2007. 165f. Dissertação (Mestrado em Educação) - Centro de Educação e Centros Humanos da Universidade Federal de São Carlos, 2007.

FREIRE, P. Pedagogia do oprimido. 15. ed. Rio de Janeiro: Paz e Terra, 2015. 
LAGO, Â. Tampinha. In: SOTO, Maristela P. A. L. (Coord.). Histórias pescadas: antologia de contistas brasileiros. São Paulo: Moderna, 2001. (Coleção Literatura em minha casa)

MACHADO, A. M. Doze reis e a moça no labirinto. São Paulo: Global Editora, 2006.

MELLO, R. R.; BRAGA, F. M.; GABASSA, V. Comunidades de aprendizagem: outra escola é possível. São Carlos: EduFSCar, 2012.

Tertúlia literária dialógica: espaço de aprendizagem dialógica, Itajaí. Contrapontos, vol. 3, n. 3, p. 449-457, set./dez. 2003. Disponível em: http://www6.univali.br/seer/ index.php/rc/article/viewFile/740/591. Acesso em: 4 jul. 2014.

VALLS Y CAROL, M. R. Comunidades de Aprendizaje: uma práctica educativa de aprendizaje dialógico para la Sociedad de la Información. 2000. Tesis (Doctoral) - Programa de Doctorado: Pedagogía Social y Políticas Sociales. Departamento de Teoría y Historia de la Educación. Universidad de Barcelona, 2000.

VILA, A.,CALLEJO A.L.,VILA, A.,CALLEJO A.L. Matemática para aprender a pensar: o papel das crenças na resolução de problemas. São Paulo:Artmed, 2006.

YESTE, C. G. Os grupos interativos: uma nova organização na aula. In: Comunidades de aprendizaje: de La segregacíon a la inclusión. Tesis doctoral para optar al título de doctora em Sociologia, 2004.

Recebido em: 18 abril 2016.

Aceito em: 28 abril 2016. 